\title{
Man of steel
}

A long and happy life?

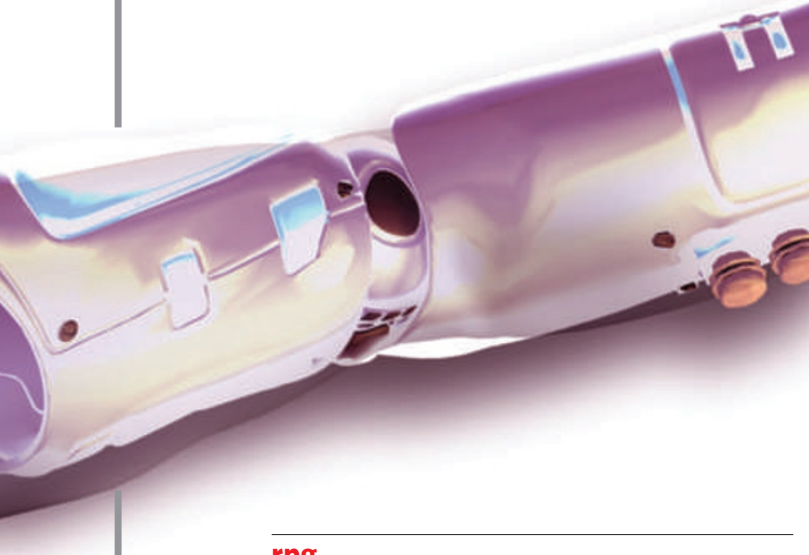

rpg

The suicide note itself wasn't particularly remarkable.

Handwritten, of course. Even the oldest computers would have detected the quiver in the voice, or parsed the strained phraseology, and automatically alerted the authorities. The blue ink scratched its way across the paper, as if hard pressed to recall the individual shapes of letters. At one point the nib had pierced the white sheet. Few people wrote regularly with pens. It was still taught at school, but the odd love letter or shopping list was as far as most people got. And suicide notes, of course. This was no different; the writing was that of the very old, or the very young.

In a way the hand was old, the oldest that had still lived. But just as the sunrise is as old as time and new each dawn, so this hand was new: three months and twelve days, according to the factory's records.

Even the words, the symbols of the man's thoughts, were not worthy of note. They would have won no literary prize; inspired no doomed, romantic quest; enquickened no tired and demoralized army. The very human story was the usual one: of love, of ennui and, ultimately, of heartbreak.

No one, least of all himself, remembered quite when or how he had lost his first hand, more than 300 years ago. The accident was recorded, but if the loose-leaf binder still existed, the cheap ink was long faded into obscurity. Sometimes he claimed it was an explosion in a fume hood; at other times a gas cylinder had fallen from its moorings and crushed him.

What his memory was clear on, and what was attested to in the medical literature, was that he had attached ('singlehandedly, haha!' he would joke) an artificial limb to the remains of his own arm. Not a simple prosthetic, but a fully functioning organ of composite fibre, ceramic joints and golden threads carrying twoway nervous traffic. The body's own electrical impulses provided power to the tiny servos that drove the slender titanium flexors and extensors.

No accident, the second prototype: it was tested and retested, planned months in advance. His wife directed the operation, and when he woke, his right arm to the shoulder was fully robotic. A fortnight later, while he was still delirious from antibiotics and analgesic, she was killed by a drunk-driver.

The record shows that he opened a new lab with venture capital, employed three dozen scientists and disappeared into his research. The exclusive clinic followed: he himself was its first patient, walking out on legs of alloyed titanium - and straight back into the lab.

Half a dozen more clinics started up across the nation, opening their doors to anyone whose medical insurance would pay the fees. For ten years the company replaced natural limbs with artificial constructs that were functionally equivalent to the original. More than equivalent: these never wore out, never got cancer, never got tired, never felt weak or cold.

For ten years the clinics operated and the lab researched. No papers were published, no patents applied for, and investors grew nervous. Interest waned. Two clinics closed; a third of the research staff was laid off. Rumours circulated, created by and lost in the noise of the Internet. It was another three years later when, finally, a press conference was called on the lawn of the first clinic, the handful of journalists who bothered to turn up were turned away - خ - and were called back, to face a man who under crepusculine clouds glistened.

The patents and the papers followed on the morrow: the artificial blood, the fuel cells, the intricate and minuscule fibres and vessels and motors: in short, a body wonderfully and fearfully man-made.

Only his face appeared natural, and over the following years even that was slowly replaced. Having no need of food, depending solely on a defined and especially formulated medium, protected by filters and powered by the elements, no toxins could threaten him. With hard, durable alloys and man-made composites in place of bones and tissues, redundant systems and every organ replaceable, he was all but indestructible.

Alzheimer's had been cured by the time he reached 105, and the last bastion of mortality - the uncontrolled cell division leading to legion neoplasms - tamed a few years after that. And then he was a living brain in a metal and plastic shell, talking, walking and living: never fatigued, immune to all disease, the Tree of Life incarnate.

For 200 years he lived like this, never needing to eat: a weekly cocktail of nutrients and pharmaceuticals keeping the one, irreplaceable fleshly and uniquely human organ alive.

When the end came it was without fanfare or press conference. No papers were written, no patent lawyers notified. With the finest of Torx drivers he opened an access panel, removed a wire, took out a power cell, held it - his life in his own hands.

The suicide note of the world's first immortal ended simply enough:

I cannot live without her.

rpg is the nom de plume of a molecular cell biologist and hopeless romantic at the University of Sydney. 